\title{
PUBLIC DIPLOMACY OF RUSSIAAND KAZAKHSTAN AS A TOOL OF STATE YOUTH POLICY FORMATION
}

\author{
Dinara N. Aytzhanova \\ Omsk State University named after F. M. Dostoevsky, Omsk, Russian Federation \\ Inna A. Vetrenko \\ Omsk State University named after F. M. Dostoevsky, Omsk, Russian Federation
}

\begin{abstract}
The article deals with the distinction between state and non-state youth policy. This approach was purposefully selected by the authors as the review of the state youth policy only through the prism of the institutional approach does not allow to understand and to comprehend other mechanisms of its formation, in addition to the ones used by state power institutions. The institutional approach also does not take into account a number of important factors, influencing youth policy formation. The authors show the differences between political-science understanding of public diplomacy and its legal, sociological and historical understanding. The article contains the identification of the nature of public diplomacy, which had emerged as a response to the global challenges and threats, to the formation of a new world order, to the course of intra-political development.

Globalization has become the main reason for public diplomacy emergence and active development. In the context of this study, public diplomacy is presented as an effective mechanism for the formation of the state youth policy of Russia and Kazakhstan. The authors show the advantages of conceptual and formal plan of public diplomacy in comparison to the official one on the example of youth policy development in the two countries. Public diplomacy appeared from the standpoint of the intra-political influence on the power institutions in the state, and the foreign policy effect in the system of international relations. The authors identify and analyze the geopolitical, historical and cultural factors that serve as preconditions for effective development of public diplomacy in the context of youth policy of Russia and Kazakhstan. The role of youth organizations in the space of the actual policy of the relationship between contemporary countries is defined and illustrated. The article gives the forecast for the development of forms and mechanisms of public diplomacy in the context of the formation of the state youth policy of the Russian Federation and the Republic of Kazakhstan. The study showed that the main tool of non-governmental youth organizations in global youth policy is the formation of international public opinion, and the integration of human resources, as important aspects of the process of development and implementation of youth policy.

Key words: youth, public diplomacy, state youth policy, state youth policy of Russia, state youth policy of Kazakhstan, non-state youth policy, non-governmental organizations.
\end{abstract}

УДК 327(091)

Дата поступления статьи: 14.06.2016

ББК 66.0

Дата принятия статьи: 02.11.2016

\section{ОБЩЕСТВЕННАЯ ДИПЛОМАТИЯ РОССИИ И КАЗАХСТАНА КАК ИНСТРУМЕНТ ФОРМИРОВАНИЯ ГОСУДАРСТВЕННОЙ МОЛОДЕЖНОЙ ПОЛИТИКИ}

\author{
Динара Нуржановна Айтжанова \\ Омский государственный университет им. Ф.М. Достоевского, г. Омск, Российская Федерация
}

Инна Александровна Ветренко

Омский государственный университет им. Ф.М. Достоевского, г. Омск, Российская Федерация 
Аннотация. В статье проведено разграничение между государственной и негосударственной молодежной политикой, такой подход авторами был выбран целенаправленно, поскольку рассмотрение государственной молодежной политики только через призму институционального подхода не позволяет понять и осмыслить другие механизмы ее формирования, помимо используемых институтами государственной власти, а также не дает возможности учесть еще ряд важных факторов, влияющих на ее формирование. Показаны отличия политологического понимания общественной дипломатии от юридического, социологического и исторического. Была выявлена природа общественной дипломатии, она появилась как форма ответа на глобальные вызовы и угрозы, на становление нового мирового порядка, на ход внутриполитического развития. Глобализация стала главной причиной ее возникновения и активного развития. В контексте данного исследования общественная дипломатия представлена как эффективный механизм формирования государственной молодежной политики России и Казахстана. Авторы показали преимущества содержательного и формального плана общественной дипломатии перед официальной на примере развития молодежной политики двух стран. Общественная дипломатия предстала с позиций как внутриполитического влияния на институты власти в государстве, так и со стороны внешнеполитического эффекта в системе международных отношений. Выявлены и проанализированы геополитические, исторические и культурные факторы, выступающие предпосылками для эффективного развития общественной дипломатии в контексте молодежной политики России и Казахстана. Определена и показана роль молодежных организаций в пространстве реально действующей политики взаимоотношений современных стран. Дан прогноз развития форм и механизмов общественной дипломатии в контексте формирования государственной молодежной политики Российской Федерации и Республики Казахстан. Исследование в рамках данной статьи показало, что основной инструмент неправительственных молодежных организаций в сфере мировой молодежной политики - формирование международного общественного мнения, а также объединение человеческих ресурсов, что является важными аспектами процесса разработки и реализации молодежной политики.

Ключевые слова: молодежь, общественная дипломатия, публичная дипломатия, государственная молодежная политика, государственная молодежная политика России, государственная молодежная политика Казахстана, негосударственная молодежная политика, неправительственные организации.

Сегодня понятие «государственная молодежная политика» входит в категориальный аппарат многих наук и отраслей. Свое понимание его содержания дают юридическая, историческая, политическая, социологическая науки. Однако в научных работах отсутствует разделение категорий «государственная молодежная политика» (ГМП) - как политики, осуществляемой государственными политическими институтами, организациями, структурами - и «негосударственная молодежная политика» (НМП). По мнению современного исследователя С.Н. Чируна, «данные обстоятельства препятствуют изучению структурно-функциональных связей, характеризующих взаимодействие государственных и общественных составляющих как подсистем в системе молодежной политики. Недостаточная дифференцированность систем ГМП и общественной молодежной политики приводит к определенным противоречиям, возникающим в процессе взаимодействия названных систем» [7, с. 18].

На наш взгляд, высказанный тезис представляется крайне важным, поскольку рассмотрение государственной молодежной политики только через призму институциональ- ного подхода не позволяет понять и осмыслить другие механизмы ее формирования, помимо используемых институтами государственной власти, не дает возможности учесть еще ряд важных факторов, влияющих на ее формирование. Прежде всего таких, что лежат за пределами официальных параметров. Одним из них является общественная дипломатия, которая оказывает мощнейшее воздействие на жизнь молодежи, особенно на приграничных территориях.

Общественная дипломатия появилась как форма ответа на глобальные вызовы и угрозы, на становление нового мирового порядка, на ход внутриполитического развития. Она родилась и получила признание в эпоху глобализации, цивилизационных сдвигов, глубоких изменений, произошедших в мире, в том числе и в психологических установках людей. В политической науке общепринятого определения понятия «общественная дипломатия» пока не существует. Для ее обозначения нередко употребляют другой термин - «публичная дипломатия».

Но мы вслед за другими отечественными политологами, такими как Р.С. Мухаме- 
тов, считаем, что необходимо проводить четкие различия между «публичной дипломатией» и «общественной дипломатией» [1].

Термин «публичная дипломатия» получил в России распространение как перевод термина «public diplomacy». Изначально он появился в одной из главных кузниц кадров Государственного департамента США Флетчеровской школе права и дипломатии (Fletcher School of Law and Diplomacy), одно из наиболее ранних определений (1965 г.) принадлежит декану Школы права и дипломатии Университета Тафта Эдмунду Галлиону (Edmund Gullion), обозначившему этим термином «программы, финансируемые правительством, направленные на информирование и воздействие на общественное мнение в других странах» (цит. по: [3]). Согласно словарю Госдепартамента, публичной дипломатией называют «финансируемые правительством программы, направленные на информирование и влияние на граждан зарубежных стран посредством публикаций, кинопродукции, обменов в области культуры, радиовещания и телевидения» (цит. по: [6, с. 106]).

Таким образом, публичная дипломатия собирательный термин, обозначающий усилия правительства, направленные на разъяснение миру проводимой им внешней политики и более глубокое ознакомление с нею народов мира с государством [4].

Тогда, в свою очередь, «общественная дипломатия - это деятельность независимых от государства некоммерческих организаций, направленная на достижение уставных целей» [3].

Одним из акторов общественной дипломатии выступают неправительственные организации (НПО). Неправительственными называют организации, которые созданы гражданами на добровольной основе для защиты общих интересов и достижения совместно общих целей.

Признаки неправительственных организаций:

- организация должна иметь некоммерческий характер, то есть получение коммерческой прибыли не ставится в качестве основной цели деятельности;

- организация должна иметь неправительственный характер, то есть государственные органы не являются участниками или учредителями организации;
- организация не должна использовать или пропагандировать насильственные методы, то есть не является террористической;

- организация не должна принимать участие в политической деятельности с целью достижения власти, то есть не является политической партией [8].

Неправительственные организации объединяют в себе довольно широкий круг организаций, описываемых, например, как фонды, ассоциации, благотворительные организации, институты, движения или союзы.

Общественная дипломатия использует, как правило, методы и формы неофициального общения и действия. К методам общественной дипломатии относят акции протеста или поддержки (они проходят в форме пикетов, митингов, маршей, собраний и т. д.) перед зданием посольства, сбор подписей, резолюции и воззвания акторов. Формой общественной дипломатии является и участие в конференциях (конгрессах, круглых столах и т. д.) [2].

В рамках заявленной нами проблемы следует отметить, что сегодня в контексте евразийской интеграции возросла роль общественной дипломатии России и Казахстана в области формирования молодежной политики двух этих стран. Сформировалось большое количество различных площадок и форматов, которые позволяют самой молодежи влиять на такие столь значимые политические процессы, как политика государства в отношении молодежи, международное сотрудничество молодежи России и Казахстана в контексте формирования новой системы мирового порядка.

Так, недавно состоялась работа очень интересной диалоговой площадки для молодежи России и Казахстана - Российско-казахстанского молодежного форума «Соседи», который проходил с 28 по 31 августа в оздоровительном лагере «Янтарь» г. Оренбурга. Организаторами выступили АНО «Содружество народов Евразии» и департамент молодежной политики Оренбургской области. Мероприятие собрало на своей площадке неравнодушных инициативных ребят: активистов молодежных организаций ведущих политических партий России и Казахстана, Российского союза молодежи, Евразийского движения, объединений «Жас Улан» («Молодое поколе- 
ние»), «Кенес» («Совет»), волонтеров студенческих отрядов.

Главными темами форума и стали сближение народов, профилактика ксенофобии, борьба с подменой гражданского патриотизма национализмом. В этих целях на протяжении четырех дней в игровой форме российские и казахстанские сверстники прошли тренинг «Наша сила в единстве народов», укрепили командный дух и сплоченность на состязаниях, ближе познакомились с этническим и религиозным богатством соседей на вечере национальных культур.

На данном форуме много внимания уделили проблеме экстремизма и религиозной ксенофобии. Молодежи доступным и понятным языком представители правоохранительных структур и правозащитники рассказали о трансграничных угрозах новых религиозных движений «Ата жол» и «Алля Аят», распространенных и в Казахстане, и в России. В итоге группы молодежи России и Казахстана сами сошлись во мнении о разрушительном характере национализма и религиозного экстремизма.

Несмотря на то что форум не включен ни в одну принятую на государственном уровне программу сотрудничества между Россией и Казахстаном, инициаторами его стали молодежные активисты двух стран, диалоговая площадка дала старт конкурсу молодежных проектов на гранты, которые будут разработаны как на федеральном, так и на региональном уровне в субъектах РФ, которые граничат с Казахстаном. Принимать в них участие может молодежь двух стран. Уже есть конкретный результат от форума как формы молодежной общественной дипломатии на официальном уровне: впервые учреждены международные молодежные гранты в России: на федеральном уровне - Фондом Горчакова, а на региональном - губернатором Оренбургской области Юрием Бергом. На наш взгляд, это только начало, но уже действенное в отношении молодежной политики двух стран соседей.

Приведенный нами пример, позволяет согласится со словами Владимира Хомерики, которые он произнес на встрече с министром иностранных дел России Сергеем Лавровым 10 апреля 2015 г.: «Общественная диплома- тия имеет ряд преимуществ перед официальной, она менее затратна, более разнообразна в используемых приемах, методах и содержании, менее стереотипна и действует с учетом различия в социокультурных условиях и традициях. Она несопоставимо более свободна в своих действиях, менее зависима от официальных решений, более рациональна с точки зрения житейского подхода к сложным проблемам межгосударственных отношений и способна на своем уровне выявить ранние, латентные стадии назревающего конфликта и осуществлять превентивные меры по его гашению» [5].

И, судя по нашему примеру, такое сотрудничество и развитие молодежной политики России и Казахстана приносит более быстрый эффект, чем громоздкие и долго принимаемые государственные и межгосударственные решения.

Очень радует и тот факт, что общественная дипломатия в молодежной среде приобретает и открывает новые формы и направления. Так, еще на одной приграничной территории Омской области, которая имеет самую протяженную границу с Казахстаном, готовится проведение аналогичного мероприятия, но уже в более широком международном формате. С 19 по 23 сентября 2016 г. в г. Омске состоялся Форум молодых лидеров ШОС, посвященный молодежному сотрудничеству между Китаем, Россией, Казахстаном, Таджикистаном, Киргизией, Узбекистаном, Индией, Пакистаном и Ираном в сфере культуры, науки, бизнеса и медиа. В Форуме приняли участие 250 человек: международные эксперты, молодые лидеры из России и стран ШОС.

Деловая программа Форума была посвящена вопросам развития молодежного сотрудничества в сфере общественной дипломатии, предпринимательства, научно-инновационной деятельности и медиакоммуникаций. Участники Форума подготовили комплексные дорожные карты реализации восьми международных совместных проектов, хотя изначально планировалось только порядка пяти.

В рамках Форума состоялась презентация и запуск таких значимых проектов, как «Энергетический студенческий бизнес-инкубатор ШОС» и «Международное молодежное информационное агентство ШОС». 
Следует отметить, что инициаторами такого масштабного мероприятия выступили активисты Общероссийской общественной организации «Российский союз молодежи», которые рассчитывали на формирование новых механизмов сотрудничества среди молодежи стран ШОС и не ошиблись. Результатами форума стали не только разработанные запущенные молодежные проекты, но и созданы постоянно действующие коллегиальные органы из числа молодежи, которые на системной основе намерены организовывать молодежное взаимодействие по различным вопросом, и прежде всего по проектной деятельности.

Общественная дипломатия использует, как правило, негосударственные (не имеющие институционального статуса) формы и методы неофициального общения и действия на различных уровнях и в рамках непрерывно разрастающейся сети НПО-сообществ, межличностных, семейных и иных отношений, с применением новейших достижений в области коммуникативных технологий и способов влияния на интеллект и психику человека, на общественное мнение. В отношении молодежи ее значимость еще усиливается тем, что данная социальная группа в большей степени подвержена неформальному влиянию и системно стремится уйти от давления на нее официальных институтов социализации. Общественная дипломатия в данном контексте выступает симбиозом, способным сочетать в себе определенную свободу от формализма и возможность молодежи самой влиять на государственную политику в отношении себя, расширяя границы понимания друг друга.

Общественная дипломатия имеет колоссальное значение и влияние как во внешней, так и внутренней политике государств. В обоих случаях, помимо организационных и финансовых, мы имеем дело с человеческими ресурсами. Это наиболее важно, поскольку таким образом общественная дипломатия выполняет свою основную миссию, особенно в отношении молодежи. Сегодня стало очевидным, что общественная дипломатия способна оказать влияние на официальную дипломатическую деятельности, а также стать инструментом формирования государственных институтов, форм государственной деятельности. Российская Федерация и Республика Казахстан имеют очень тесную связь между собой, не только территориальную, но историческую и культурную, поэтому общение между ними всегда проходило как на формальном, так и не на неформальном уровне, особенно если это касается воспитания и взаимоотношений молодого поколения. Сами политические и социальные процессы между двумя этими странами, такие как образовательная и трудовая миграция, формирование новых форматов межрегионального сотрудничества, делают общественную дипломатию в области молодежной политики необходимой и актуальной. Зачастую сегодняшний опыт показывает нам, что многое форматы сотрудничества среди молодежи России и Казахстана сначала запускаются и апробируются на уровне совместных общественных проектов, а затем уже становятся официальными формами государственных и межгосударственных отношений.

\section{СПИСОК ЛИТЕРАТУРЫ}

1. Долинский, А. Что такое общественная дипломатия и зачем она нужна России? / А. Долинский. - Электрон. текстовые дан. - Режим доступа: http://russiancouncil.ru/inner/?id_4=791 (дата обращения: 25.08.2016). - Загл. с экрана.

2. Медведева, Т. И. Основные методы и формы гражданской дипломатии в современном политическом процессе / Т. И. Медведева. - Электрон. текстовые дан. - Режим доступа: http://www.drzzd. de/nikon_16.htm (дата обращения: 25.08.2016). - Загл. с экрана.

3. Мухаметов, Р. С. Общественная дипломатия: сущность, акторы и методы работы / Р. С. Мухаметов // Развитие политических институтов процессов и технологий: отечественный и зарубежный опыт. - Омск : Изд-во ОмГУ, 2013. - С. 99-103.

4. Хайд, Г. Д. Разговор с нашими безмолвствующими союзниками: общественная дипломатия и внешняя политика США / Г. Д. Хайд. - Электрон. текстовые дан. - Режим доступа: http://www.if.tsu. ru/Sokol/USA4.htm (дата обращения: 20.07.2016).Загл. с экрана.

5. Хомерики, В. Общественная дипломатия как важный фактор мироустройства / В. Хомерики. - Электрон. текстовые дан. - Режим доступа: http:/ /ruskline.ru/special_opinion/2015/04/obwestvennaya_ diplomatiya_kak_vazhnyj_faktor_miroustrojstva/ (дата обращения: 15.06 .2016 ). - Загл. с экрана.

6. Цатурян, С. А. Общественная дипломатия США в новом информационном столетии / С. А. Ца- 
турян // США - Канада. Экономика, политика, культуpa. -2010. - № 8. - С. 105-115.

7. Чирун, С. Н. Молодежная политика в ситуации постмодернизма (государство, власть, общество) : автореф. дис. ... д-ра полит. наук / Чирун Сергей Николаевич. - Казань, 2016. - 43 с.

8. Шершнев, И. Л. Роль неправительственных организаций в институализации Российской общественной дипломатии / И. Л. Шершнев // Знание. Понимание. Умение. - Электрон. текстовые дан. Режим доступа: http://cyberleninka.ru/article/n/rolnepravitelstvennyh-organizatsiy-v-institualizatsiirossiyskoy-obschestvennoy-diplomatii (дата обращения: 01.09.2016). - Загл. с экрана.

\section{REFERENCES}

1. Dolinskiy A. Chto takoe obshchestvennaya diplomatiya i zachem ona nuzhna Rossii? [What is Public Democracy and Why does Russia Need It?]. Available at: http://russiancouncil.ru/inner/?id_4=791. (accessed August 25, 2016).

2. Medvedeva T.I. Osnovnye metody i formy grazhdanskoy diplomatii $v$ sovremennom politicheskom protsesse [Main Methods and Forms of Civil Diplomacy in the Contemporary Political Process]. Available at: http://www.drzzd.de/ nikon_16.htm. (accessed August 25, 2016).

3. Mukhametov R.S. Obshchestvennaya diplomatiya: sushchnost, aktory i metody raboty [Public Diplomacy: Subject Matter, Actors and Tools]. Razvitie politicheskikh institutov protsessov $i$ tekhnologiy: otechestvennyy i zarubezhnyy opyt [Development of Political Institutions, Processes and
Technologies: National and Foreign Experience]. Omsk, 2013,pp. 99-103.

4. Khayd G.D. Razgovor s nashimi bezmolvstvuyushchimi soyuznikami: obshchestvennaya diplomatiya $i$ vneshnyaya politika SShA [A Conversation with our Silent Allies: the US Public Diplomacy and Foreign Policy]. Available at: http://www.if.tsu.ru/Sokol/USA4.htm. (accessed July 20, 2016).

5. Khomeriki V. Obshchestvennaya diplomatiya kak vazhnyy faktor miroustroystva [Public Diplomacy as an Important Factor of the World Order]. Available at: http://ruskline.ru/special_opinion/2015/04/ obwestvennaya_diplomatiya_kak_vazhnyj_faktor_ miroustrojstva/. (accessed June 15, 2016).

6. Tsaturyan S.A. Obshchestvennaya diplomatiya SShA v novom informatsionnom stoletii [US Public Diplomacy in the New Information Century]. SShA - Kanada. Ekonomika, politika, kultura, 2010, no. 8, pp. 105-115.

7. Chirun S.N. Molodezhnaya politika $v$ situatsii postmodernizma (gosudarstvo, vlast, obshchestvo): avtoref. dis. ... d-ra polit. nauk [Youth Policy in the Postmodernism (State, Power, Society). Dr. polit. sci. abs. diss.]. Kazan, 2016. 43 p.

8. Shershnev I.L. Rol nepravitelstvennykh organizatsiy $\mathrm{v}$ institualizatsii Rossiyskoy obshchestvennoy diplomatii [The Role of NonGovernmental Organizations in the Institutionalization of Russian Public Diplomacy]. Znanie. Ponimanie. Umenie, 2012, no. 1. Available at: http:// cyberleninka.ru/article/n/rol-nepravi-telstvennyhorganizatsiy-v-institualizatsii-rossiyskoyobschestvennoy-diplomatii. (accessed September 1, 2016).

\section{Information about the Authors}

Dinara N. Aytzhanova, Postgraduate Student, Department of Political Science, Omsk State University named after F.M. Dostoevsky, Prosp. Mira, 55, 644077 Omsk, Russian Federation, aytzhanova.di@mail.ru, http://orcid.org/0000-0003-2811-2461.

Inna A. Vetrenko, Doctor of Sciences (Politics), Professor, Head of Department of Political Science, Omsk State University named after F.M. Dostoevsky, Prosp. Mira, 55, 644077 Omsk, Russian Federation, Inna-Vetrenko@yandex.ru, http://orcid.org/0000-0001-5212-4580.

\section{Информация об авторах}

Динара Нуржановна Айтжанова, аспирант кафедры политологии, Омский государственный университет им. Ф.М. Достоевского, просп. Мира, 55, 644077 г. Омск, Российская Федерация, aytzhanova.di@mail.ru, http://orcid.org/0000-0003-2811-2461.

Инна Александровна Ветренко, доктор политических наук, профессор, заведующая кафедрой политологии, Омский государственный университет им. Ф.М. Достоевского, просп. Мира, 55, 644077 г. Омск, Российская Федерация, Inna-Vetrenko@yandex.ru, http://orcid.org/0000-0001-5212-4580. 